\title{
SISTEM INFORMASI PENGAJUAN CUTI BERBASIS WEBSITE DAN PENERAPAN SMS GATEWAYNOTIFICATION PT. BANK NEGARA INDONESIA (PERSERO) TBK KANTOR CABANG TANJUNG PINANG
}

\author{
${ }^{1}$ Ade Winarni, ${ }^{2}$ Endah Fri Handayani \\ Sekolah Tinggi Teknologi Indonesia \\ e-mail : ${ }^{1}$ adewina16@gmail.com, ${ }^{2}$ Endahfrihandayani@gmail.com
}

\begin{abstract}
ABSTRAK
Sistem informasi merupakan suatu tatanan yang terdiri atas organisasi, prosedur, himpunan data dan sumber daya manusia yang mampu menghasilkan dan menyajikan informasi yang akurat dan efektif untuk mendukung berbagai upaya dan pengelolaan data dalam rangka mewujutkan peningkatan dan pertumbuhan instansi atau perusahan pada bidangnya masing-masing.
\end{abstract}

Dimana masing-masing pegawai kantor tersebut dapat mengajukan cuti sesuai peraturan yang sudah ditetapkan oleh perusahan seperti cuti tahunan, cuti nikah dan cuti melahirkan serta cuti haji dengan ketentuan jumlah hari cuti (waktu masa cuti) seperti dibawah ini :

1. Cuti Tahunan memiliki waktu masa cuti yang disesuaikan dengan masa kerja pegawai seperti : Masa kerja 1-5 tahun sebanyak 12 hari kerja dalam setahun, Mada kerja 5-10 tahun sebanyak 15 hari kerja dalam setahun, Masa kerja 10 tahun dst sebanyak 18 hari kerja dalam setahun.

2. Cuti Nikah memiliki waktu masa cuti sebanyak 3 hari kerja.

3. Cuti Melahirkan memiliki waktu masaa cuti sebanyak 3 bulan.

4. Cuti Haji memiliki waktu masa cuti sebanyak 40 hari.

Dimana setiap data pengajuan cuti karyawan pada masing-masing kantor cabang pembantu dan karyawan kantor cabang utama direkap kedalam Microsoft excel dan setiap formulir permohonan cuti masih direkap secara manual. Dengan keadaan seperti gambaran diatas maka tidak menutup kemungkinan akan terjadi kesalahan pada proses pendataan dan bahkan formulir dapat hilang. Sehingga karyawan yang sebenarnya mendapat persetujuan cuti, bisa saja tercecer atau hilang dan bahkan dapat digantikan dengan karyawan yang sebenarnya belum bisa mendapat cuti.

Sehingga pada saat ini pengelolaan data permohonan cuti dilakukan secara manual, dimana proses pengiriman formulir dan surat keputusan pengajuan cuti menggunakan sarana email dan via telepon atau sms. Sehingga mengakibatkan kinerja Bag. Unit Umum menjadi lambat serta menghabat pekerjaan yang lainnya, karena semua proses dilakukan oleh Bag. Unit Umum. Sehingga pada saat ini system terkomputerisasi sangat dibutuhkan oleh instansi terkai agar dapat 
membantu memperkecil kesalahan dan mempermudah, serta mempercepat kinerja Bag. Unit Umum dalam proses pengeloaan data permohonan cuti

Dengan kondisi diatas maka penulis menuangkan inisiatif untuk membuat sebuah system yang mampu memadai semua proses pengelolaan data permohonan cuti dengan menggunakan metode Waterfall dalam perancanganan perangkat lunak yang akan digunakan oleh semua Pegawai dan Bag. Unit Umum. Agar lebih memudah dan dapat diakses kapan dan dimana saja sistem dirancang berbasis website dan menggunaka SMS Gateway, sehingga notifikasi pemberitahuan langsung dikirim secara otomatis oleh system tersebut pada masing-masing pegawai yang telah melakukan permohonan baik permohonan tersebut disetujui atau ditolak. Dalam perancangan system penulis mengunakan PHP (Programing Hypertext Prepocessor), framework (LARAVEL) dan SMSGateway.ME sebagai media perancangan system.

Kata Kunci : Sistem Informasi Pengelolaan Data Permohonan Cuti Pegawai Bank BNI Berbasis Website dan SMS Gateway.

\section{PENDAHULUAN}

Dengan perkembangan teknologi informasi yang berorientasi pada sistem terkomputerisasi yang sudah merupakan tuntutan disegala bidang maka sama halnya dengan PT. Bank Negara Indonesia (Persero) Tbk Kantor Cabang Tanjungpinang khususnya pada Unit Umum Kantor Cabang Utama yang membutuhkan sebuah sistem pengelolaan data yang berkaitan dengan pengambilan cuti bagi semua pegawai. Yang mana pada saat ini masih menggunakan sistem (program) berbasis descktop yang belum memiliki fitur atau layanan pengiriman atau pengajuan cuti bagi pegawai pada masing-masing Kantor Cabang Pembantu.

Dimana masing-masing karyawan Kantor Cabang Pembantu dan Kantor Cabang Utama memiliki beberapa jenis cuti yang memiliki batas waktu dan batas jumlah karyawan yang dapat mengajukan cuti pada masing-masing kantor. Serta pengelolaan atau pendataan data pengambilan cuti belum memiliki fitur yang dapat menyediakan informasi bagi semua karyaan tentang jumlah dan jenis cuti yang masih belum diambil dan yang sudah diambil, serta pemberahuan bahwa pengajuan cuti disetujui atau tidak.

Dengan kondisi atau situasi pendataan pengajuan cuti dengan jumlah yang banyak dan kantor yang berbeda-beda, serta jarak yang jauh maka pengelolaan data pengajuan cuti tersebut belum terlaksana dengan baik dan memudahkan para pegawai dalam melakukan proses pengajuan cuti. Semua hal tersebut terjadi karena 
system atau program yang digunakan masih menggunaka MicrosoftExcel yang dilakukan secara manual.

\section{KAJIAN PUSTAKA}

\subsection{Definisi Sistem}

Sistem adalah sekelompok unsur yang erat hubungannya satu dengan yang lain, yang berfungsi bersama-sama untuk mencapai tujuan tertentu. Secara sederhana sistem dapat diartikan sebagai suatu kumpulan atau himpunan dari unsur, komponen, atau variabel-variabel yang terorganisasi, saling berinteraksi, saling tergantung satu sama lain dan terpadu yang bertujuan untuk menyediakan informasi untuk membantu mengambil keputusan dalam suatu perusahaan atau organisasi.

\subsection{Karateristik Sistem}

1. Komponen Sistem (Components)

Suatu sistem terdiri dari sejumlah komponen yang saling berinteraksi, artinya saling bekerja sama membentuk satu kesatuan. Komponenkomponen sistem tersebut dapat berupa suatu bentuk subsistem, setiap subsistem memiliki sifat dari sistem yang menjalankan suatu fungsi tertentu dan mempengaruhi proses sistem secara keseluruhan, suatu sistem dapat mempunyai sistem yang lebih besar atau sering disebut "supra sistem".

2. Batasan Sistem (Boundary)

Ruang lingkup sistem merupakan daerah yang membatasi antar sistem dengan sistem yang lain atau sistem dengan lingkungan luarnya, batasan sistem ini memungkinkan suatu sistem dipandang sebagai satu kesatuan yang tidak dapat dipisahkan.

3. Lingkungan Luar Sistem (Environtment)

Bentuk apapun yang ada diluar ruang lingkup atau batasan sistem yang mempengaruhi operasi sistem tersebut disebut lingkungan luar sistem, lingkungan luar sistem ini dapat bersifat menguntungkan dan dapat juga bersifat merugikan sistem tersebut. Dengan demikian, lingkungan luar tersebut harus tetap dijaga dan dipelihara, lingkungan luar yang merugikan harus dikendalikan, jika tidak akan mengganggu kelangsungan hidup sistemtersebut.

4. Penghubung Sistem (Interface)

Media yang menghubungkan sistem dengan subsistem lain disebut penghubung sistem atau interface, penghubung ini memungkinkan sumbersumber daya mengalir dari satu subsistem ke subsistem lain. Bentuk 
keluaran dari satu subsistem akan menjadi masukan untuk subsistem lain melalui integrasi sistem yang membentuk suatu kesatuan.

5. Masukkan Sistem (Input)

Energi yang dimasukkan kedalam sistem disebut masukkan sistem, yang dapat berupa pemeliharaan (maintenanceinput) dan sinyal (sinyal Input). Contoh, di dalam suatu unit sistem komputer "program" adalah maintenance input yang digunakan untuk mengoperasikan komputernya dan "data" adalah signal input untuk diolah menjadi informasi.

6. Keluaran Sistem (Output)

Hasil energi yang diolahdan diklasifikasikan menjadi keluaran yang berguna, keluaran ini merupakan masukan bagi subsistem yang lain seperti sistem informasi. Keluaran yang dihasilkan adalah informasi, informasi ini dapat digunakan sebagai masukkan untuk pengambilan keputusan atau halhal yang menjadi input bagi subsistem lain.

7. Pengolahan Sistem (Proses)

Suatu sistem dapat mempunyai suatu proses yang akan mengubah masukan menjadi keluaran, contohnya adalah sistem akuntansi. Sistem ini akan mengolah data transaksi menjadi laporan-laporan yang dibutuhkan oleh pihak manajemen.

8. Sasaran Sistem (Objective)

Suatu sistem memiliki tujuan dan sasaran yang pasti dan bersifat deterministic, jika suatu sistem tidak memiliki sasaran maka operasi sistem tidak ada gunanya. Suatu sistem dikatakan berhasil bila mengenai sasaran atau tujuan yang telah direncanakan.

\subsection{Klasifikasi Sistem}

Adapun klasifikasi system yang dimaksut adalah sebagai berikut:

1. Sistem abstrak

sistem berupa pemikiran atau ide-ide yang tidak tampak secara fisik, misalnya sistem teologia, yaitu sistem yang berupa pemikiran hubungan antara manusia dengan Tuhan, sedangkan sistem fisik merupakan sistem yang ada secara fisik, misalnya sistem komputer, sistem produksi, sistem penjualan, sistem administrasi personalia, dan lain sebagainya

2. Sistem alamiah

sistem yang terjadi melalui proses alam, tidak dibuat oleh manusia, misalnya sistem perputaran bumi, terjadinya siang malam, dan pergantian musim. Sedangkan sistem buatan manusia merupakan sistem yang melibatkan interaksi manusia dengan mesin yang disebut human machine sistem. Sistem informasi berbasis komputer merupakan contoh human 
machine sistem karena menyangkut penggunaan komputer yang berinteraksi dengan manusia.

3. Sistem tertutup merupakan sistem yang tidak berhubungan dan tidak terpengaruh oleh lingkunagn luarnya. Sistem ini bekerja secara otomatis tanpa campur tangan pihak luar. Sedangkan sistem tebuka adalah sistem yang berhubungan dan dipengaruhi oleh lingkungan luarnya. Sistem ini menerima masukan dan menghasilkan keluaran untuk sub sistem lainnya.

Berikut ini merupakan kualitas dari system :

1. Akurat (accuracy) : Informasi harus bebas dari kesalahan-kesalahan dan tidak menyesatkan. Informasi harus akurat karena biasanya dari sumber informasi sampai penerima informasi adakemungkinan terjadi gangguan (noise) yang dapat mengubah atau merusak informasi tersebut.

2. Tepat Pada Waktunya (Accuracy) : Informasi yang datang pada penerima tidak boleh terlambat. Informasi yang sudah usang tidak akan mempunyai nilai lagi, karena informasi merupakan landasan didalam pengambilan keputusan. Bila pengambilan keputusan tersebut terlambat, maka dapat berakibat fatal untuk organisasi.

3. Relevan (Relevance) : Informasi tersebut mempunyai manfaat untuk pemakainya. Relevansi informasi untuk tiap-tiap orang satu dengan yang lainnya berbeda.

Adapun pengertian system infomasi menurut Robert A. Leich adalah suatu system didalam suatu oraganisasi yang mempertemukan kebutuhan pengolahan transaksi harian, mendukung operasi, bersifat manejerial dan kegiatan strategi dari suatu organisasi dan menyediakan pihak luar tertentu dengan laporan-laporan yang diperlukan.

\subsection{Cuti Karyawan/Pegawai}

Menurut Peraturan Pemerintah Nomor 24 Tahun 1976, Cuti adalah keadaan tidak masuk kerja yang diijinkan dalam jangka waktu tertentu. Cuti terdiri dari :

1. Cuti Tahunan : Setiap Pegawai Negeri Sipil yang telah bekerja sekurangkurangnya satu tahun secara terus menerus berhak atas cuti tahunan. Lamanya Cuti tahunan adalah 12 (dua belas) hari kerja. Cuti Tahunan tersebut dapat diambil secara terpecahpecah, dengan ketentuan setiap bagian tidak boleh kurang dari 3 (tiga) Hari kerja.

Cuti tahunan yang tidak diambil dalam kurun waktu 2 (dua) tahun berturut-turut atau lebih, dapat diambil dalam tahun berikutnya untuk paling lama 24 (dua puluh empat) hari kerja, termasuk cuti tahunan dalam tahun yang sedang berjalan.

2. Cuti Besar : Cuti besar adalah cuti yang dapat diambil oleh seorang PNS setelah bekerja 6 tahun berturut-turut. Lama cuti besar adalah maksimal 90 hari kalender.

3. Cuti Sakit : Cuti sakit adalah cuti yang bisa diambil oleh seorang PNS ketika sakit dan membutuhkan waktu istirahat untuk pemulihan kondisinya. 
4. Cuti bersalin : Cuti bersalin adalah cuti yang dapat diambil oleh PNS wanita untuk melahirkan anak pertama, kedua, dan ketiga. Lama cuti bersalin adalah maksimal 90 hari kalender.

5. Cuti Karena Alasan Penting : PNS dapat cuti karena alasan penting untuk paling lama 60 hari kalender. Lamanya cuti karena alasan penting hendaknya ditetapkan sedemikian rupa, sehingga benar-benar hanya untuk waktu yang diperlukan saja. Dalam kondisi tertentu, cuti alasan penting hanya bisa diambil setelah hak cuti pegawai yang bersangkutan tidak mencukupi lagi/habis.

\subsection{SMS Gateway}

SMS gateway adalah sebuah sistem aplikasi yang digunakan untuk mengirim dan menerima SMS, dan biasanya digunakan pada aplikasi bisnis, baik untuk kepentingan broadcast promosi (Bulk SMS), servis informasi terhadap pengguna, penyebaran content produk/jasa dan lain-lain. Pada umumnya SMS gateway memiliki ada dua cara yang digunakan untuk membangun SMS gateway tersebut :

1. Menggunakan perangkat tambahan berupa modem dan aplikasi pendukung seperti Gammu.

2. Menggunakan layanan berbayar pihak ketiga seperti Raja SMS atau Zenziva.

Masing-masing kedua cara diatas memiliki kekurangan dan kelebihan salah satu diantaranya adalah sebagai berikut :

1. Seperti perangkat tambahan modem misalnya. Kita harus menancapkan modem tersebut pada sebuah PC atau laptop yang digunakan selama 24 jam penuh (atau selama SMS akan digunakan). Hal ini seperti kita membangun server mini untuk sebuah task khusus. Kelebihannya, kita bisa mengontrol SMS masuk maupun keluar sesuai keinginan.

2. Lain lagi dengan layanan menggunakan pihak ketiga. Cara ini terbilang mudah digunakan. Kita cukup mengirim SMS secara programatically ke server mereka, sisanya sistem dan perangkat mereka yang akan mengirimkan SMS ke penerima. Kekurangannya, harga per SMS-nya jauh lebih mahal dibandign SMS reguler.

Aplikasi SMS Gateway adalah sebuah perangkat lunak yang menggunakan bantuan komputer dan memanfaatkan teknologi seluler yang diintegrasikan guna mendistribusikan pesan-pesan yang dipadukan lewat sistem informasi melalui media SMS yang ditangani oleh jaringan seluler.

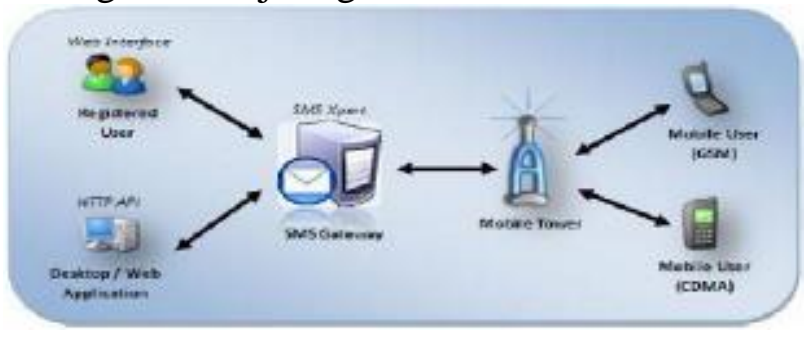

Gambar 2.1 Skema SMS Gateway

Mekanisme kerja pengiriman SMS dibagi menjadi 3 bagian yaitu :

1.Intra-operator SMS: pengiriman SMS dalam satu operator.

2.Inter-operator SMS: pengiriman SMS antar operator yang berbeda. 
3.SMS Internasional: pengirim SMS dari operator suatu negara ke negara.

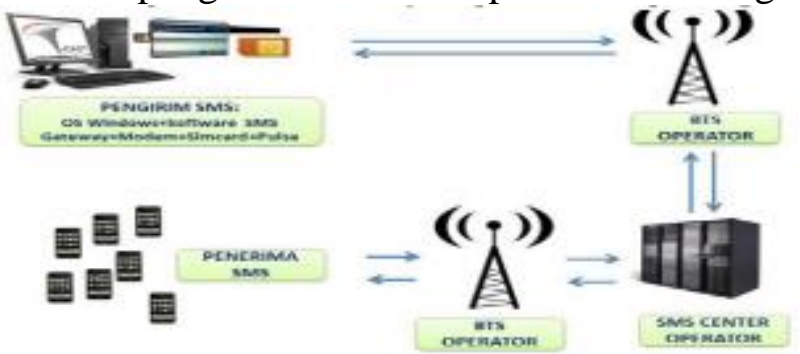

Gambar 2.2 Cara Kerja SMS Gateway

\section{METODOLOGI PENELITIAN}

\subsection{Metodologi Pengumpulan Data}

1. Studi Pustaka yaitu untuk mengumpulkan data dan informasi yang berhubungan dengan masalah yang dibahas, dengan cara membaca dan memahami literature-literature dari beberapa buku.

2. Studi Lapangan yaitu suatu cara yang dilakukan untuk mendapatkan datadata dan informasi, serta keterangan yang relevan dan akurat mengenai masalah yang diteliti antara lain sebagai beriut :

a. Wawan Cara adalah teknik pengumpulan data dengan cara memberikan beberapa pertanyaan langsung kepada pihak yang terkait maupun staf perusahaan atau instansi yang bersangkutan.

b. Observasi (memantau)adalah teknik pengumpulan data dengan melakukan pengamatan secara langsung atau turun kelokasi penelitian untuk mendapatkan data dan informasi yang lebih banyak dan akurat.

\subsection{Metodologi Pengembangan Perangkat Lunak}

Metode pengembangan perangkat lunak yang digunakan dalam membangun sistem informasi ini menggunakan model Waterfall (Classic Life Cycle) yang menyarankan pengembangan perangkat lunak secara sistematik dan berurutan yang dimulai dari tingkatan sistem tertinggi dan berlanjut ke tahap analisis, desain, pengkodean, pengujian dan pemeliharaan. Kelebihan dari metode ini adalah terstruktur,dinamis dan sequential.

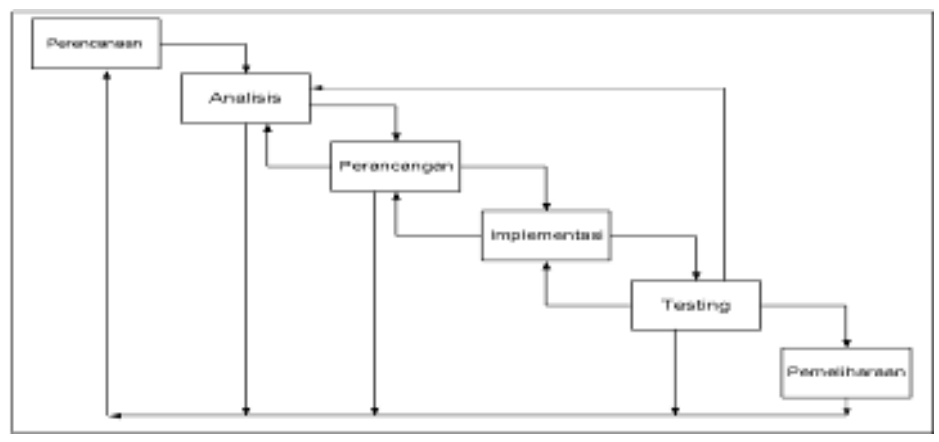

Gambar1.1 Metode Wateffall 


\subsection{Analisis Sistem Yang Sedang Berjalan}

1. Flowmap Pengajuan Cuti Pada KCP Yang Sedang Berjalan

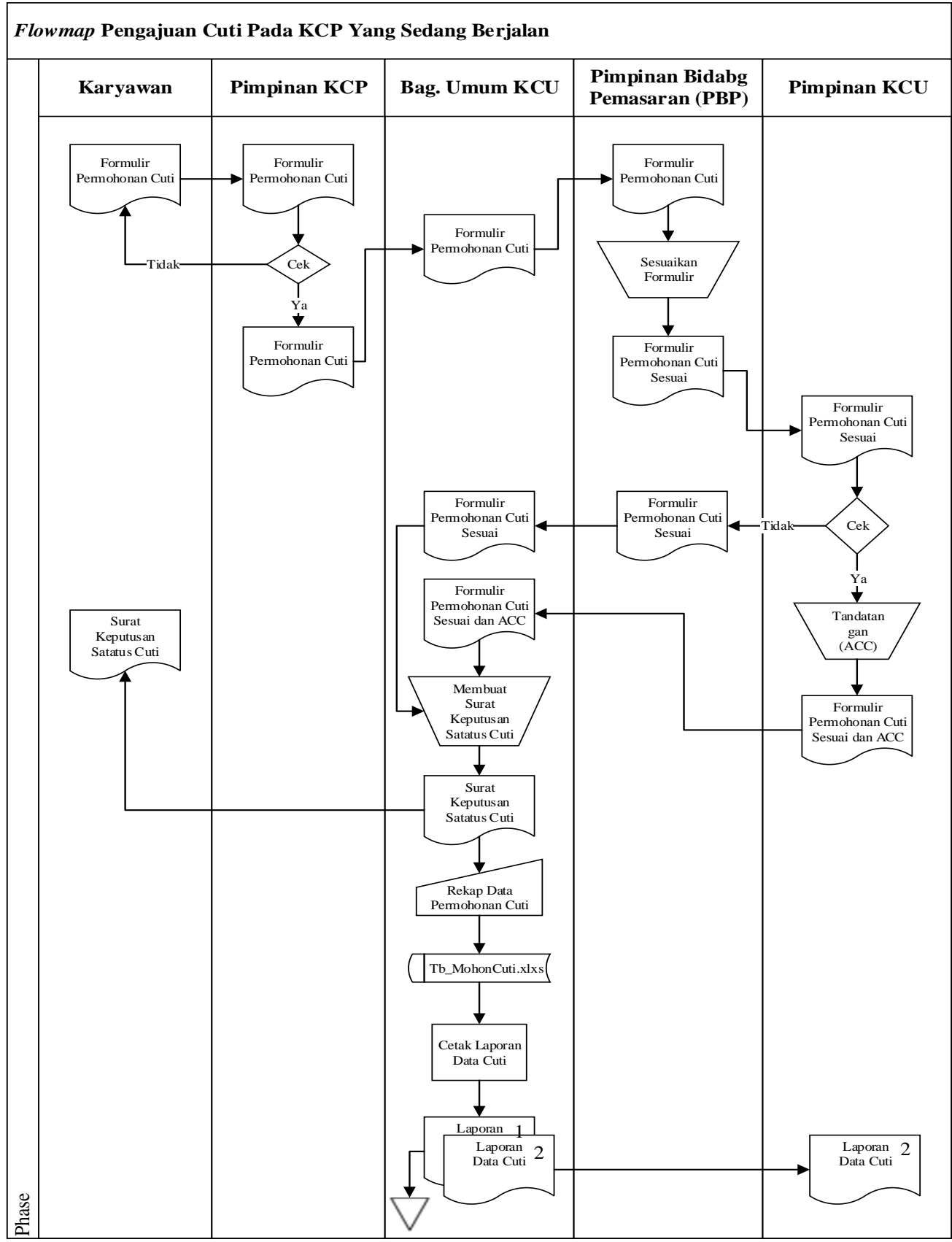

Gambar 3.1 Flowmap Permohonan cuti Karyawan KCP

2. Flowmap Pengajuan Cuti Pada KCU Yang Sedang Berjalan 


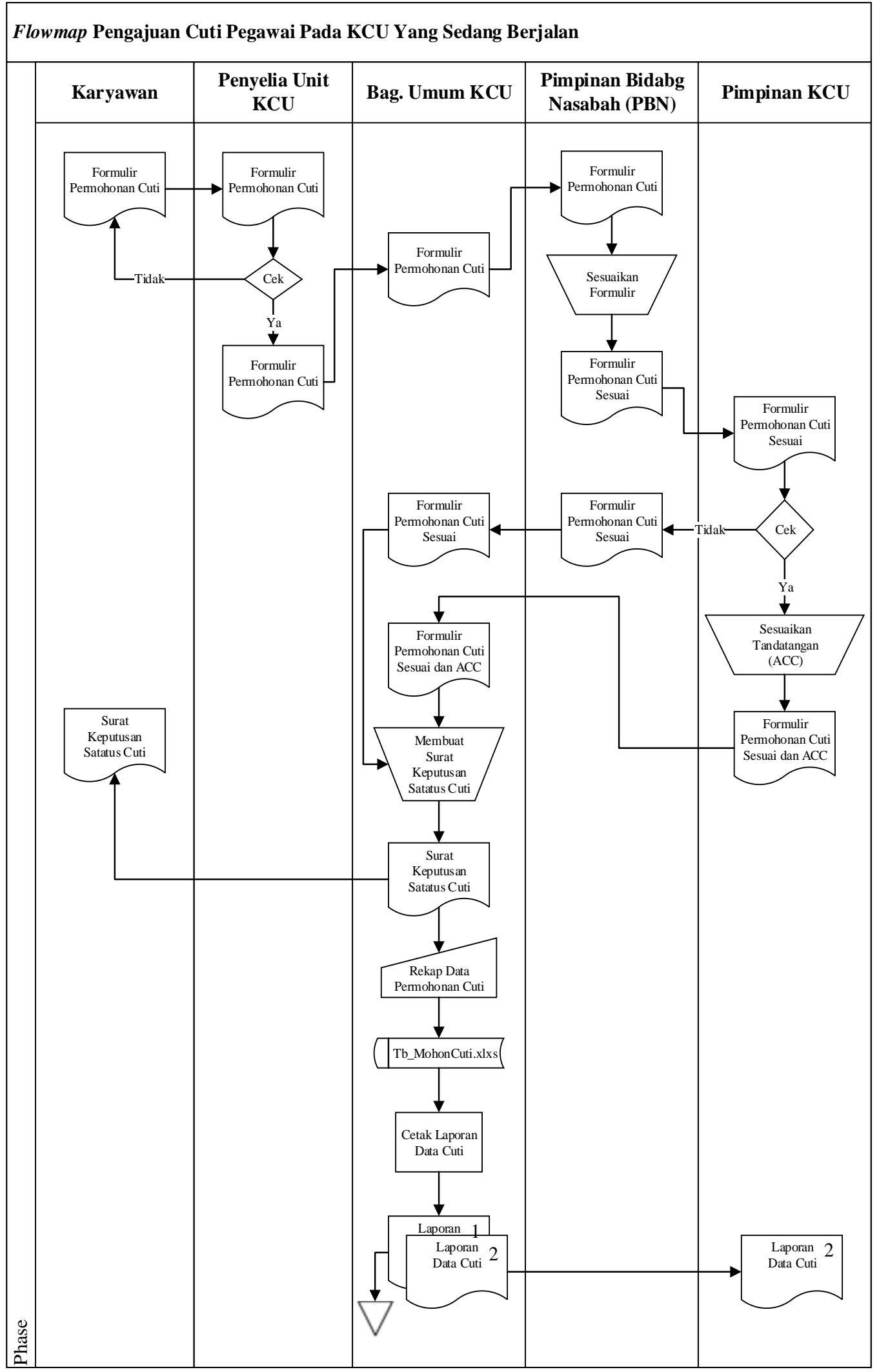

Gambar 3.2 Flowmap Permohonan cuti Karyawan KCU 


\subsection{Analisis Dokumen}

Berdasarkan analisis aliran dokumen diatas maka penulis menemukan beberapa dokumen keluar dan dokumen masukan pada sistem Pengelolan Aset pada PT. Bank Negara Indonesia (Tbk) Persero Kantor Cabang Tanjungpinang, yang sedang berjalan saat ini, sebagai berikut :

1. Dokumen Masukan

a. Formulir pegajuan cuti (Surat Permohonan)

Dokumen tersebut berisikan tetang nama, jumlah hari cuti, jenis cuti, jabatan dan data kantor cabang dari masinng-masing karyawan yang akan mengajukan cuti. Kemudian formulir tersebut diserahkan ke Bag. Umum KCU agar diproses yang dikirim via e_mail.

Tabel 3.1 Formulir Permohonan Cuti

\begin{tabular}{|l|l|l|l|l|}
\hline NO & Nama Dokumen & \multicolumn{3}{|c|}{ Uraian (Keterangan) } \\
\hline \multirow{2}{*}{1} & $\begin{array}{l}\text { Formulir } \\
\text { Permohonan Cuti }\end{array}$ & Fungsi & $:$ & Bukti Permohonan Cuti. \\
\cline { 3 - 5 } & Rangkap & $:$ & 1 (Satu) \\
\cline { 3 - 5 } & Atribut & $:$ & $\begin{array}{l}\text { Nama, Npp, Garade/Posisi, Unit } \\
\text { Organisasi, Jenis Cuti, Jumlah Hari, } \\
\text { Tanggal Pengambilan Cuti, } \\
\text { Keperluan, Alamat Cuti, } \\
\text { Permohonan Lain, Catatan UMC. }\end{array}$ \\
\cline { 3 - 5 } & Aliran data & $:$ & $\begin{array}{l}\text { Dari Karyawan (Pegawai) ke Bag. } \\
\text { Umum KCU. }\end{array}$ \\
\hline
\end{tabular}

2. Dokumen Keluaran

a. SuratPersetujuan Cuti

Dokumen ini berisikan data dan ketentuan mengenai pengajuan dan persetujuan cuti yang diajukan oleh masing-masing pegawai sebelumnya dan surat persetujuan ini dibuat atau dicetak oleh Bag. Unit Umum. Seanju di kirim melalui via E-Mail atau hanya diarsipkan oleh Bag. Unit Umum kemudian Bag. Unit Umum merekap (simpan) data tersebut ke dalam Microsoft Excel.

Tabel 3.2 Surat Persetujuan Cuti 


\begin{tabular}{|c|c|c|c|c|}
\hline NO & Nama Dokumen & \multicolumn{3}{|r|}{ Uraian (Keterangan) } \\
\hline \multirow{4}{*}{1} & \multirow{4}{*}{$\begin{array}{l}\text { Surat Persetujuan } \\
\text { Cuti }\end{array}$} & Fungsi & : & Bukti Persetujuan Cuti. \\
\hline & & Rangkap & : & 1 (Satu) \\
\hline & & Atribut & 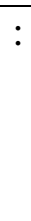 & $\begin{array}{l}\text { Tanggal, No, Hal, Kepada, Unit } \\
\text { Organisasi, Jenis Cuti, Jumlah Hari, } \\
\text { Tanggal Masuk, Alamt Cuti, dan } \\
\text { Jenis Cuti. }\end{array}$ \\
\hline & & Aliran data & : & Dari Bag. Unit Umum Ke Pegawai. \\
\hline
\end{tabular}

\section{HASIL DAN PEMBAHASAN}

\subsection{Perancangan Sistem Yang Diusulkan}

Perancangan system merupakan suatu bentuk hasil yang diperoleh melalui proses analisis prosedur dari system yang sedang berjalan yang akan disajikan dalam beberapa betenk analisis seperti : flowmap usulan, diagram konteks, data flow diagram dan entity relationship serta flowchart diagram seperti gambar dibawah ini

1. Flowmap Permohonan Pengajuan Cuti Yang Diusulkan 


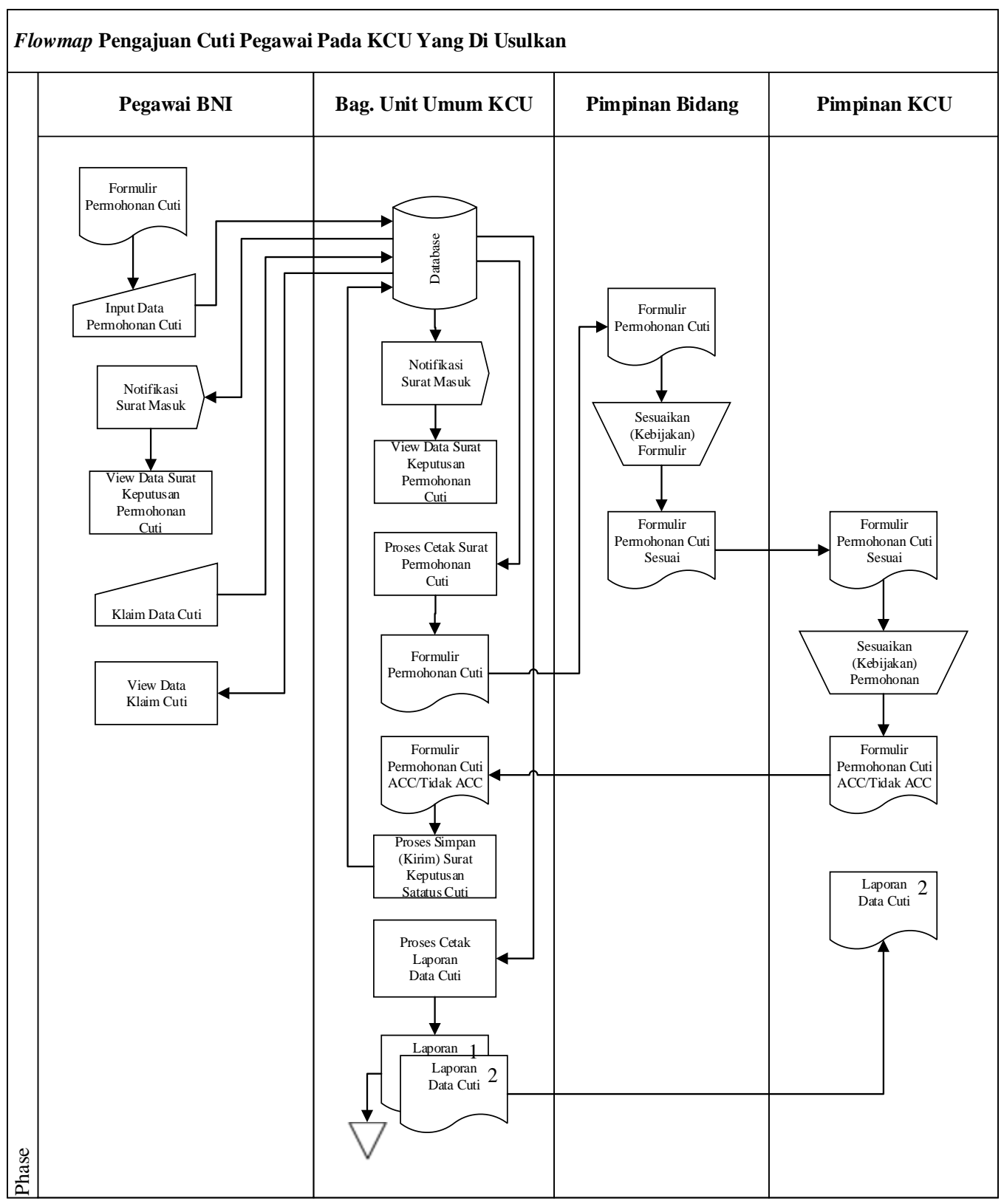

Gambar 4.1 Flowmap Permohonan Pengajuan Cuti Pegawai

2. Diagram Konteks 


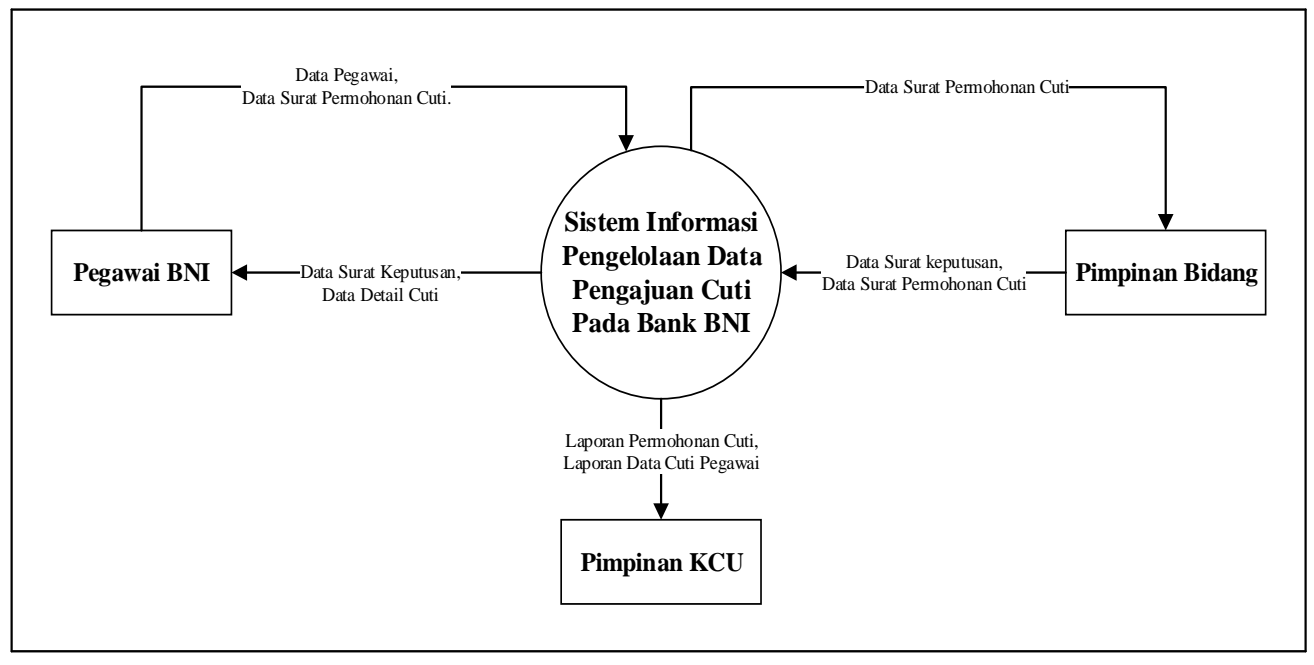

Gambar 4.2 Diagram Konteks

3. Data Flow Diagram



Gambar 4.3 Data Flow Diagram Level 0 Pengelolaan Data Permohonan Cuti

4. Entity Relation Diagram 


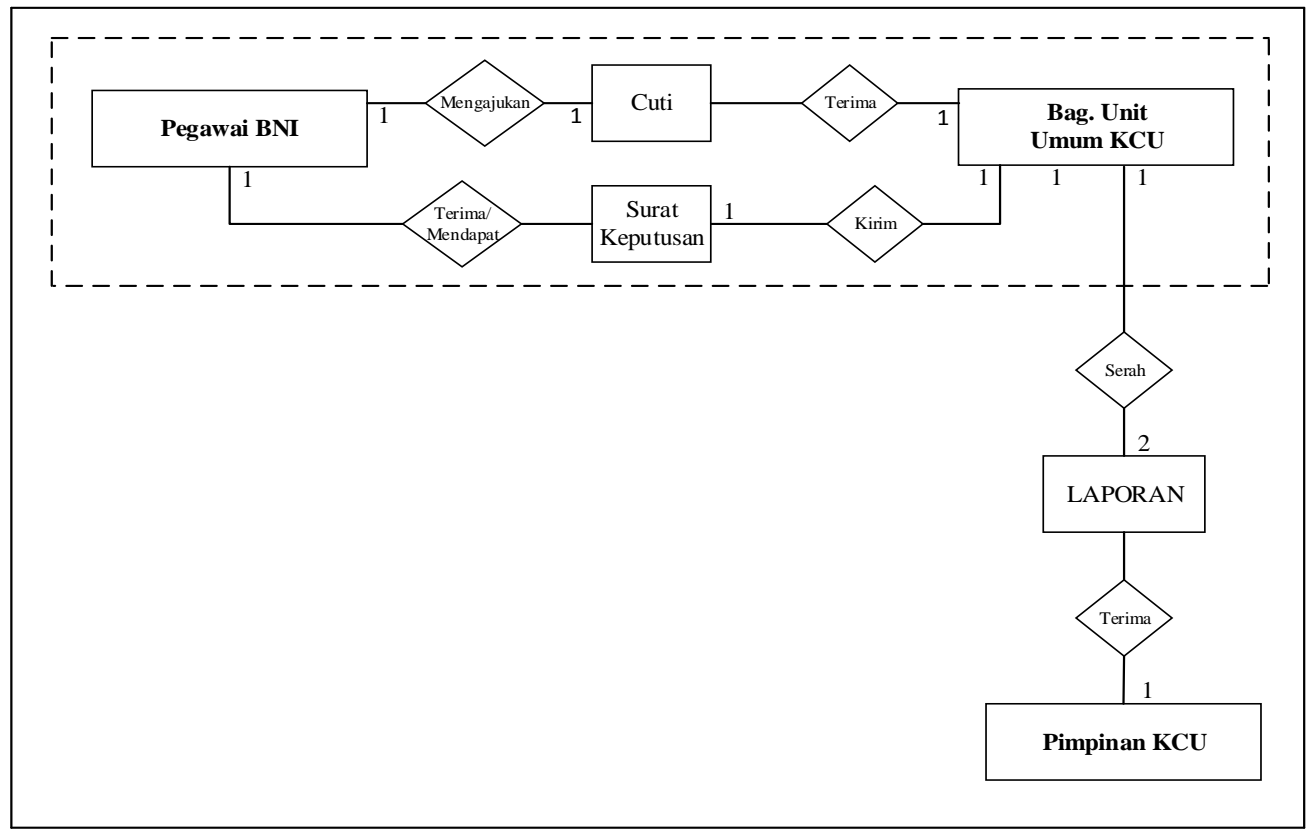

Gambar 4.4 Entity Relationship Diagram

5. Flowchart Pengiriman SMSPemberitahuan Status Cuti

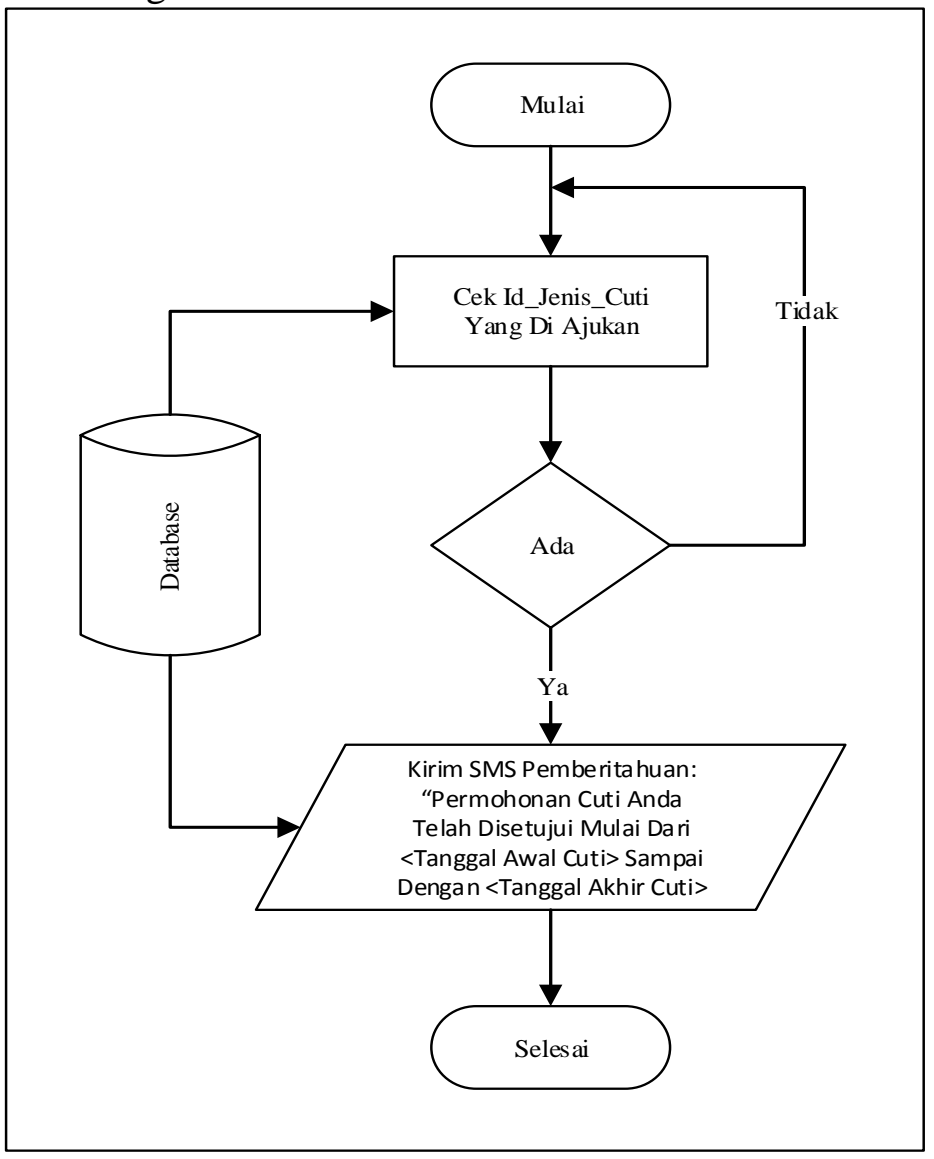


Gambar 4.5 Flowchart Pengiriman SMS Pemberitahuan Status Cuti

\subsection{Implementasi}

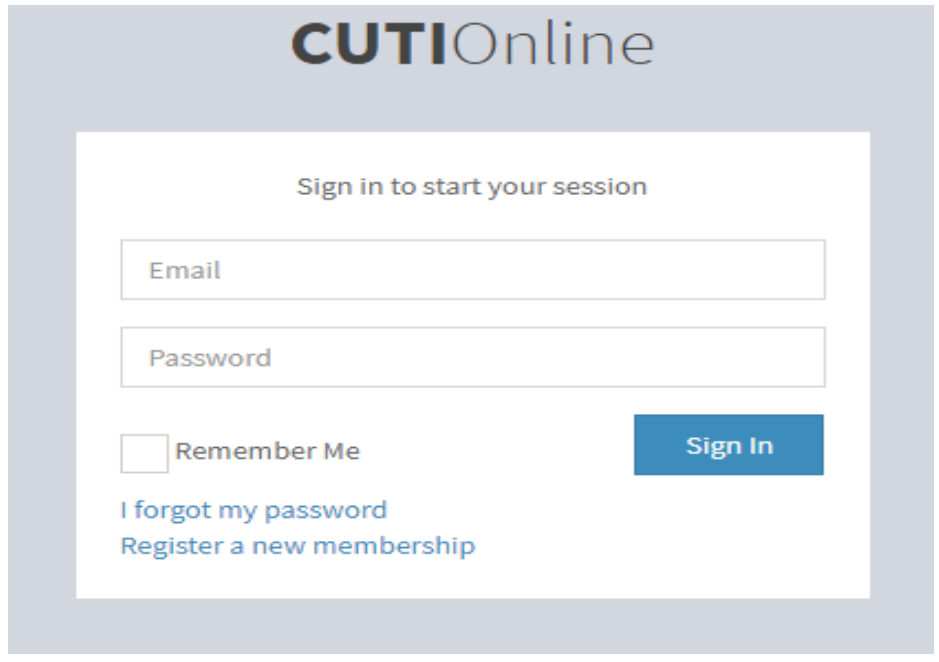

Gambar 5.1 Form Login

1. ImplementasiIntevace Bag. Unit Umum (Admin)

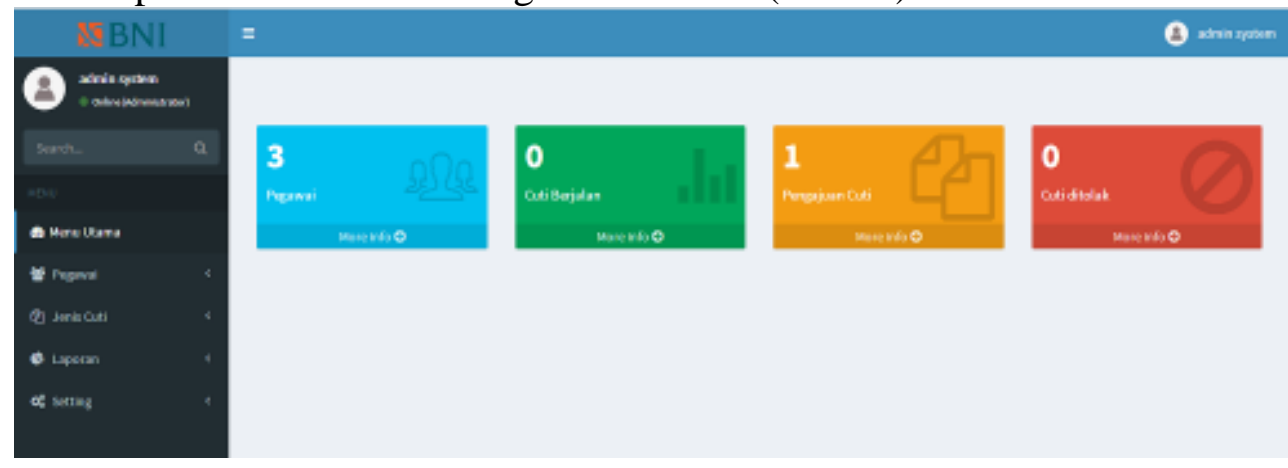

Gambar 5.2 Halaman Utama 


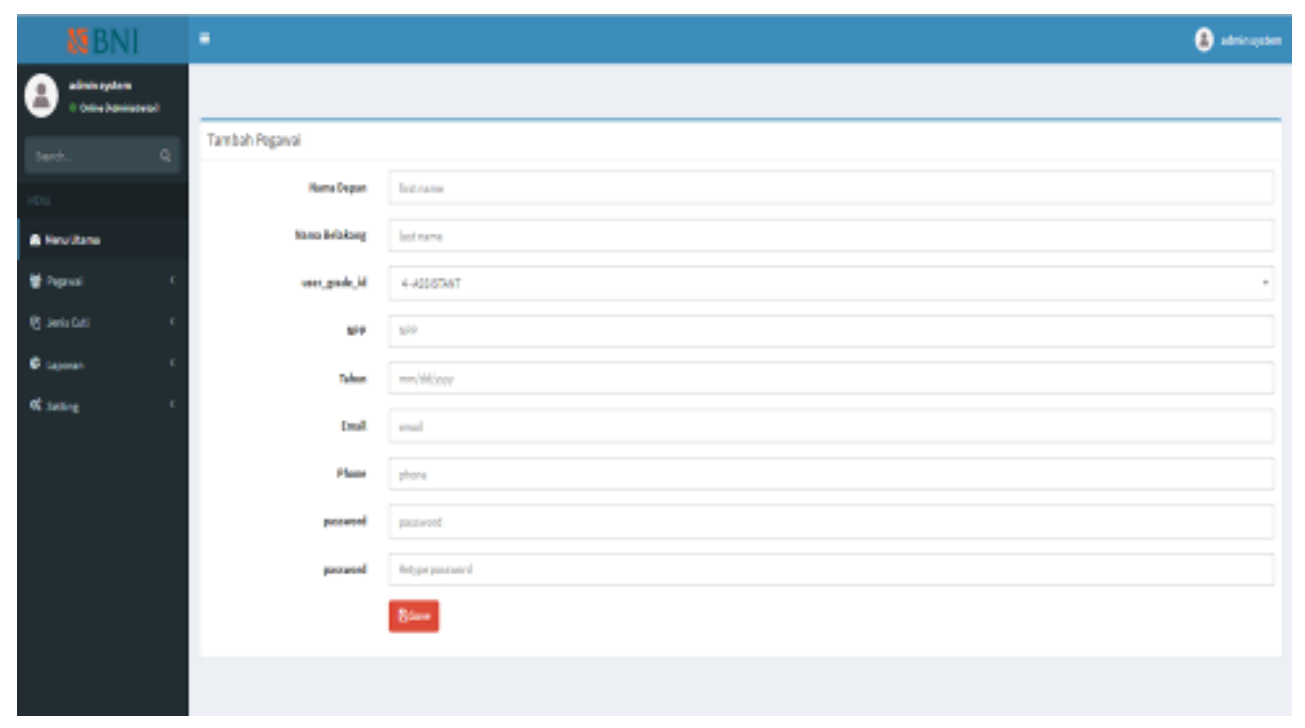

Gambar 5.3 Halaman Form Tambah Pegawai

\section{KESIMPULAN}

Setelah melakukan beberapa rangkaian proses implementasi dan pengujian pada Sistem Informasi Pengajuan Cuti Pada PT. Bank Negara Indonesia (Persero) Tbk Kantor Cabang Tanjungpinang, maka penulis dapat membuat beberapa kesimpulan sebagai berikut :

1. Data yang tersimpan sudah menggunakan database.

2. Proses pengiriman surat permohonan dari masing-masing Kantor Cabang Pembantu ke Kantor Cabang Utama sudah terkomputerisasi.

3. Proses pendataan atau pengelolaan Cuti sudah terkomputerisasi.

4. Proses pembuatan laporan menjadi lebih mudah, cepat dan akurat.

Berikut ini adalah beberapa saran yang penulis cantumkan dalam sistem atau aplikasi yang telah dibuat untuk perkembangan sistem kedepannya agar menjadi lebih baik, antara lain :

1. Penambahan fitur konrol jarak jauh untuk melakukan maintenance pada tiap-tiap kantor.

2. Penambahan fitur alaram atau sumber suara pada notifikasi surat masuk yang terpasang dalam sistem.

3. Penambahan formchat masing-masing pegawai dengan admin sistem (Bag. Unit Umum).

4. Melakukan pelatihan terlebih dahuulu kepada pengguna system sebelum menggunakan sistem. 


\section{DAFTAR PUSTAKA}

Sekolah Tinggi Teknologi Inndonesia Tanjungpinang, Buku Panduan Penulisan Laporan Kerja Praktek (KP) dan Skripsi, [2014].

Nugroho

Adi,

AnalisisdanPerancanganSisitemInformasidanMetodologiBerorientasiObje

$\mathrm{k}$, Bandung, Informatika Bandung [t.th].

http://digilib.uinsby.ac.id,M.Mu'alimah"PERAN SISTEM INFORMASI

MANAJEMEN (SIM)", [Agustus 05 2017].

http//:parno.staff.gunadarma.ac.id/Downloads/folder/0.11"Analisis dan

Perancangan Sistem Informasi”, [September 01 2017].

http//:JURNAL TEKNIK POMITS "Pembuatan Sistem Informasi Cuti pada

Kantor Pelayanan Perbendaharaan Negara dengan Menggunakan PHP dan

MySQL", [September 01 2017].

http://e-journal.uajy.ac.id/7619/1/Jurnal.pdf, Kajian Yuridis Terhadap Hak Cuti

Tahunan dan Kopensasi Akibat Pemutusan Kerja Secara Sepihak oleh

Pengusaha Bagi Pekerja Waktu Tertentu (PWKT), [September 01 2017].

https://www.laravel.web.id/2016/11/16/membangun-sms-gateway-dengan-

android-smsgateway-dan-laravel, (September 06 2017).

http://ejournal.unsri.ac.id/index.php/jsi/index,Jurnal Sistem Informasi (JSI),

VOL. 7, NO. 2, [Oktober 2015].

Haris Saputro, Modul Pembelajaran Praktek Basis Data (MySQL).

http://parno.staff.gunadarma.ac.id/SI_01_Konsep_Dasar_SI.pdf, [September $012017]$.

http://ilmuti.org/wp-content/uploads/2014/05/Henni-Handayani-XAMPP.pdf,

[September 012017$].$

http://ilmuti.org/wp-content/uploads/2014/05/Henni-Handayani-XAMPP.pdf,

[September 01 2017].

http://Jurnal- xampppaket-apache-php-dan-mysql-instant, "Xampp:Paket

Aphace, Php dan Mysql Instant”, [September 09 2017].

http://lug.stikom.edu/wp-content/media/Fitur-Dahsyat-Sublime-Text-3.pdf,

[Miftah Faridl.Tahun 2015 Edisi Pertama].

Indrajani, S.Kom., MM. Perancangan Basis Data Dalam All Im 1

[Gramedia,Jakarta 2011].

http://Jurnal-eprints.dinus.ac.id/12183/1/jurnal_12089.pdf[September092017]. 